Title: Survival at 10 years following lower extremity amputations in patients with diabetic foot disease.

Running Title: Survival at 10 years following lower extremity amputations in diabetic foot disease.

Authors: ${ }^{1}$ Bernard Pac Soo MBChB, ${ }^{1}$ Satyan Rajbhandari MD, FRCP, ${ }^{2}$ Ansy Egun

FRCS, ${ }^{1}$ Ushank Ranasinghe MBChB, ${ }^{3}$ Ian M Lahart, PhD, ${ }^{1}$ Joseph M Pappachan MD, FRCP

Author affiliations: ${ }^{1}$ Department of Medicine \& Endocrinology, Lancashire Teaching Hospitals NHS Foundation Trust, United Kingdom

${ }^{2}$ Department of Vascular Surgery, Lancashire Teaching Hospitals NHS Foundation Trust, United Kingdom, PR2 9HT

${ }^{3}$ Faculty of Education, Health and Wellbeing, University of Wolverhampton, Walsall, UK

Corresponding author: Dr. Joseph M Pappachan, MD, FRCP,

Department of Medicine \& Endocrinology, Lancashire Teaching Hospitals NHS

Foundation Trust, United Kingdom, PR2 9HT; E-mail: drpappachan@ yahoo.co.in;

https://orcid.org/0000-0003-0886-5255

Funding: No funding received for this work

Conflicts of interest: There no competing interests to declare among authors of this work

Article word counts: Abstract 240; Main text 1950 


\title{
Survival at 10 years following lower extremity amputations in patients with diabetic foot disease.
}

\begin{abstract}
Background Amputations are associated with markedly reduced long-term survival in patients with diabetic foot disease. However, there is paucity of long-term survival data in published literature.
\end{abstract}

Methods We searched the electronic case records and laboratory details of patients who underwent amputations between 1997 and 2006 to obtain at least 10 years of follow up data after the surgery to assess the survival rates and possible risk factors reducing survival in the year 2016. Amputation level below ankle was considered as minor and above ankle as major amputations.

Results Of the 233 cases (159 males; median age 68 years), 161 had major amputations. Of the 72 cases who had minor amputations initially, 63 needed a further amputation or contralateral amputation on follow up. One hundred seventy-seven patients $(76 \%)$ were not alive after 10 years of follow up. The survival rates at 1, 3, 5, 7 , and $\geq 10$ years were $64 \%, 50 \%, 40 \%, 34 \%$, and $24 \%$, respectively. Maximum number of deaths occurred within 4 months of amputations. There was no difference between survival rates following major or minor amputations and among males or females. The only statistically significant parameter affecting lower survival rate was age $\geq 70$ years, with each additional year of age increasing the hazard by a factor of 1.039 (95\% CI: $1.024-1.054)$ or $3.9 \%(2.4-5.4 \%)$.

Conclusions Five-year and 10-year survival rates were $40 \%$ and $24 \%$, respectively, following diabetic foot amputations. Higher age $\geq 70$ years was associated with lower survival rate compared with younger age groups after lower extremity amputations.

Key words: diabetic foot ulcer, lower extremity amputations, survival rate 


\section{Introduction}

Diabetes mellitus (DM) increases the risk of foot ulceration with $6 \%$ of patients having a diabetic foot ulcer (DFU) at any point of time 1, and $19-34 \%$ of diabetic patients likely to develop a foot ulceration in their lifetime ${ }^{2}$, with high recurrence rates, and marked reduction of short-term and long-term survival in affected individuals ${ }^{3}$. As a consequence of DFUs, many patients would require lower extremity/digital amputations. Compared with the nondiabetic populations, DM cases have $\sim 30$ times greater lifetime risk of amputations that substantially increase the economic burden of global healthcare systems ${ }^{4,5}$. Currently, DM is also established as the leading cause of lower extremity amputations ${ }^{6}$. Recurrence rate of DFU is high, and more than $50 \%$ of patients with DFUs will have an amputation in their lifetime ${ }^{7}$. The total healthcare expenditure related to DFUs and amputations in England alone between 2010 and 2011 was estimated at $£ .580 .5$ million ${ }^{8}$. This expenditure is expected to increase further in future owing to the steady increase in the incidence of DM.

Both DFUs and DFU-related amputations greatly reduce the survival rates in patients. The reported 30-day survival rate following DFU-related amputations was 93.7 $79.7 \%$ in a recent multinational cohort study. ${ }^{9}$ The survival rate following lower extremity amputations decreases steadily over time. The unadjusted 5-year and 10year survival rates were $61 \%$ and $33 \%$ respectively in a previous study ${ }^{10}$ which were lower than the corresponding survival rates for those with breast cancer $(90 \%$ and $83 \%$ respectively $)^{11}$ and colorectal cancer (64\% and 58\% respectively). ${ }^{12}$ The risk factors associated with reduced survival rates after lower extremity amputations were above-knee amputations, post-operative cardiac complications, higher age, renal 
failure, male gender, Hispanics, and associated peripheral vascular disease. ${ }^{10,13,14}$ Although diabetic foot disease and DFU-related lower extremity amputations are common problems in day-to-day clinical practice, there is paucity of long-term follow-up survival data after foot-amputations in the global scientific literature. Therefore, we report the results of a 10-year follow-up survival data after lower extremity amputations from a regional tertiary care center in the UK. The study also investigated the possible risk factors associated with reduced survival after amputations and compared the survival rates following minor and major amputations.

\section{Materials and methods}

After obtaining approval from the audit department, a list of diabetic patients who had undergone amputations at the Lancashire teaching Hospitals NHS Trust, between 1997 and 2006, were collected retrospectively in 2016 to allow a minimum follow-up period of at least ten years following the surgery. This Hospital Trust has 2 acute care hospitals (Chorley District Hospital and Royal Preston Hospital) with a total of 750 inpatient beds. These two hospitals provide healthcare for a population of 300,000 across Central Lancashire including comprehensive diabetic foot care. Patients from the neighboring district hospitals with diabetic foot disease are also often referred to this tertiary vascular center of this hospital Trust. These patients are then referred back to the referring hospitals after their surgery including amputations.

The foot care team involves diabetologists, diabetes nurse specialists, podiatrists, orthotists, vascular surgeons, and orthopedic surgeons. Decisions regarding a foot amputation are based on this multi-disciplinary team plan for the optimal care of patients with diabetic foot disease. 
The clinical information, demographics (such as age and gender), and the laboratory data of patients treated during the above period were collected using the electronic databases (Evolve and Quadramed) of the hospital, and all the clinic letters were searched to gather full information about the care each patient received during and following the amputations. An amputation higher than the level of the ankle was regarded as a major amputation, whereas any amputation below the ankle was categorized as a minor amputation. All the relevant investigations to document anemia, renal impairment, albumin levels, glycated hemoglobin (HbA1c) and lipids at the time of amputations were collected. Type of operations in each patient, and presence/ absence of any cancer was assessed.

Only hemoglobin levels after the amputation was considered because any source of infection present at the time of amputation could have possibly caused a drop in hemoglobin levels and would not necessarily mean that the patient was anemic. Normal reference hemoglobin values for men are 130-180 g/L and115-165 g/L for women. Renal impairment was assessed by recording creatinine levels, and values between 59-104 $\mu \mathrm{mol} / \mathrm{L}$ were considered normal. Albumin levels recorded before and after the surgery were averaged, and values $35-50 \mathrm{~g} / \mathrm{L}$ were considered normal. HbA1c levels of $\leq 7.5 \%$ in patients with co-morbidities were considered optimal control of DM. Cholesterol levels $<5 \mathrm{mmol} / \mathrm{L}$ were regarded as normal while levels $\geq$ $5 \mathrm{mmol} / \mathrm{L}$ were viewed as high. Those cases with insufficient follow up data and those from out of hospital catchment area whose current status could not be assessed were excluded from the study.

\section{Statistical analysis}


Descriptive categorial variables are shown as counts and percentages, whereas continuous variables are summarized using median and ranges (not normally distributed) or mean \pm standard deviation (normally distributed). Welch's t-tests were performed to investigate age differences between amputation type received and sex. We generated Kaplan-Meier estimators and curves to assess the influence of amputation, and type of amputation (major vs. minor), sex (female vs. male), and age ( $\geq 70$ vs. $<70$ years) on survival. Cox proportional hazard ratios were generated to assess whether age at amputation (univariate, model 1), and age at amputation, amputation type, sex, anemia, dyslipidemia, liver dysfunction, renal impairment, and poor glycemic control (model 2) influenced survival postamputation. The statistical significance level was set at $\mathrm{p}<0.05$, and we did not adjust for multiple comparisons. Statistical analysis was performed using Rstudio version 1.2.5019 (survival analysis and plots) and Jamovi version 1.1.7.0 (descriptive analysis and t-tests).

\section{Results}

Out of 387 cases that were retrieved from the electronic data search who had undergone amputations during the study period, $233(60 \%)$ cases with sufficient follow up data were included in the analysis. Most patients were males ( $\mathrm{n}=159$; $68 \%$ ), and the median age of patients was 69 years (range 29-95 years) with 111 $(48 \%)$ cases aged at least 70 years. Almost $58 \%$ of patients $(n=134)$ had major amputations and 99 had minor amputations. Out of these minor amputations, 63 cases needed a more proximal amputation or contralateral amputation subsequently and were still grouped as minor due to the index amputation status. There were no age differences between female and male patients (Welch's $t=0.83, p=.41$ ) or by amputation type received (Welch's $t=1.59, p=.11$ ). 
We recorded 177 (76\% of patients) deaths during the study period (start January 1997; end of follow up, June 2016). The median follow-up for all patients was 3 (IQR=0-11) years, but was $14(11-16)$ years for those alive at follow-up and $1.5(0$ 4) years for those who died. The greatest number of deaths $(n=84 ; 47.5 \%$ of all deaths) occurred within the first year following the amputation and most of these $(\mathrm{n}=$ 63; $36.6 \%$ of all deaths) were within first 4 months of the surgery (Fig. 1). The survival rate over 10-year follow-up period was as follows: end of first year-64\%, 3 years $-50 \%, 5$ years $-40 \%, 7$ years $-34 \%, 10$ years $-28 \%$, and $10+$ years $-24 \%$. Figure 2 shows the overall survival curve following amputations at $10+$ years after the index surgery, and Table 1 shows long-term survival characteristics of the whole cohort.

There was no statistically significant overall survival difference between major and minor surgery, with 116 (72\% of patients) and 61 (69\%) deaths reported after major and minor amputation, respectively [major vs. minor, median (interquartile range; IQR) years survival = $3(2-4)$ years vs. $5(3-7)$ years, Fig. 3]. Similarly, we observed similar survival for female and male patients throughout the study period, with 56 (74\%) deaths in female patients and second model with all covariates included, older age at amputation, again, statistically lowered survival, and having no renal impairment but having dyslipidemia statistically improved survival (Table 2). The pvalues for dyslipidemia and renal impairment, however, were just under the 0.05 threshold and we did not adjust for multiple comparisons, therefore, there is a high risk these two findings may be false positives. The more complex model (model 2) provided only a slightly better fit (concordance index $=0.712$ vs. 0.645 for model 1 ). 
Due to the retrospective design of the present study, a large proportion of cases had insufficient laboratory data for full assessment of comorbid illnesses and their influence on mortality. Only 122 (52\%) cases each had data on renal impairment and liver dysfunction (albumin levels) at the time of amputations in the electronic records. Data on anemia, HbA1c, and dyslipidemia were available only in 121 (52\%), 102 (44\%), and $99(42 \%)$ cases respectively. Just $72(31 \%)$ cases analyzed had all the parameters tested. Nine cases had cancer recorded in their clinical data although the influence of cancer on the mortality risk was unclear in the case records. Of those patients with relevant data, 89 (74\%) had anemia, 28 (28\%) had dyslipidemia, 59 (48\%) had liver dysfunction, 63 (52\%) had renal impairment, and $55(54 \%)$ had poor glycemic control (high HbA1C levels).

\section{Discussion}

Our retrospective study results provide a comprehensive picture on the survival rates among patients who underwent lower extremity amputations between 1997 and 2006 that cover follow up period more than 10-year for a total of 233 patients as follows: patients alive at the end of one year $-64 \%, 3$ years $-50 \%, 5$ years $-40 \%, 7$ years $34 \%$ and $10+$ years $-24 \%$. In our analysis, the only statistically significant parameter that affected survival was age at amputation 70 years or over. Each additional year of age after 70 years increased the hazard of death by a factor of 1.039 or $3.9 \%$.

There is wide discrepancy in the long-term survival rates among different cohorts of patients reported from various regions of the world owing to the study characteristics evaluated in the subjects studied. ${ }^{10,13,15-18}$ For instance, we observed a $10+$ year 
survival rate of $24 \%$ in our cohort, while McEwen. et al. ${ }^{10}$ and López-de-Andrés. et al. ${ }^{15}$ reported survival rates of $33 \%$ and $51.4 \%$ respectively in their studies. While we found a 5-year survival rate of $40 \%$, that observed by McEwen. et al., ${ }^{10}$ LópezValverde. et al., ${ }^{13}$ Gök. et al., ${ }^{16}$ Huang. et al., ${ }^{17}$ and Wilbek. et al. ${ }^{18}$ were $61 \%, 55.5 \%$, $30 \%, 40 \%$ and $58 \%$ respectively. Co-morbid disease states and cardiovascular factors inherent to diabetic foot disease might explain these wide discrepancies in the survival rates.

The statistically significantly lower long-term survival rate we observed among the older subjects who underwent amputations in our study cohort had also been previously reported in other studies, ${ }^{13,17-19}$ although some other researchers did not find this association. ${ }^{15,17}$ Although we did not find any statistically significant difference between minor and major amputations on long-term survival, other workers reported lower survival rates associated with major amputations. ${ }^{10,16,17}$ Renal impairment ${ }^{4,13,19}$ male gender, ${ }^{10,19}$ and anemia ${ }^{20}$ were the risk factors associated with lower survival rates among patients who underwent diabetic foot amputations reported by other studies. Although renal impairment appeared to lower survival in our analysis, this observation was likely erroneous as mentioned above. We did not find any statistically significant effect of gender difference or anemia on survival rate in our cohort. We could not also find any statistically significant association of poor glycemic control on the mortality risk in this study population.

We acknowledge that our study has several limitations. Because of the design (case note review), we could not obtain robust information about some of the laboratory variables for all the patients. This would have had an impact on the parameters we 
analyzed that might affect the survival. For example, although lack of renal impairment and cholesterol level above $5 \mathrm{mmol} / \mathrm{l}$ appeared to confer survival advantage in our analysis, these were very likely falsely positive. The cause of death could not be verified in most of the cases because of the lack of availability of the same in the hospital electronic data. A large proportion of cases (154 out of 387) who had amputations in the study period did not have follow up in the 2 hospitals where the study was conducted because their follow up were in the hospitals where they were referred from. Despite these limitations, our large cohort study gives valuable information regarding long-term survival data of diabetic foot amputations that should alert clinicians involved in the care of DFUs to risk stratify their patients and optimize the management.

\section{Conclusions:}

Diabetic lower extremity amputations were associated with a 5-year survival rate of $40 \%$ and 10 -year survival rate of $24 \%$. Mortality rates were maximum in the first 4 months after amputations. Higher age at amputation and hypoalbuminemia were associated with lower survival rates. Large multicenter long-term follow up studies are necessary to address the lack of adequate knowledge in survival trends following foot amputations.

\section{References:}

1. Mishra SC, Chhatbar KC, Kashikar A, Mehndiratta A. Diabetic foot. BMJ. 2017; 359: j5064. doi: 10.1136/bmj.j5064. PMID: 29146579. 
2. Armstrong DG, Boulton AJM, Bus SA. Diabetic Foot Ulcers and Their Recurrence. N Engl J Med. 2017; 376: 2367-2375. DOI: 10.1056/NEJMra1615439. PMID: 28614678

3. Brennan MB, Hess TM, Bartle B, Cooper JM, Kang J, Huang ES, Smith M, Sohn MW, Crnich C. Diabetic foot ulcer severity predicts mortality among veterans with type 2 diabetes. J Diabetes Complications. 2017; 31: 556-561. DOI: 10.1016/j.jdiacomp.2016.11.020. PMID: 27993523

4. Tentolouris N, Al-Sabbagh S, Walker MG, Boulton AJ, Jude EB. Mortality in diabetic and nondiabetic patients after amputations performed from 1990 to 1995: a 5-year follow-up study. Diabetes Care 2004; 27: 1598-1604. DOI: 10.2337/diacare.27.7.1598; PMID: 15220234

5. Moxey PW, Gogalniceanu P, Hinchliffe RJ, Loftus IM, Jones KJ, Thompson MM, Holt PJ. Lower extremity amputations--a review of global variability in incidence. Diabet. Med. 2011; 28: 1144-53. DOI: 10.1111/j.14645491.2011.03279.x; PMID: 21388445

6. Margolis DJ, Jeffcoate W. Epidemiology of foot ulceration and amputation: can global variation be explained? Med Clin North Am. 2013; 97: 791-805. DOI: 10.1016/j.mcna.2013.03.008. PMID: 23992892

7. Boulton AJ. The pathway to foot ulceration in diabetes. Med Clin North Am. 2013; 97: 775-790. DOI: 10.1016/j.mcna.2013.03.007. PMID: 23992891

8. Kerr M, Rayman G, Jeffcoate WJ. Cost of diabetic foot disease to the National Health Service in England. Diabet Med. 2014; 31: 1498-504. DOI: 10.1111/dme.12545. PMID: 24984759

9. Behrendt CA, Sigvant B, Szeberin Z, Beiles B, Eldrup N, Thomson IA, Venermo M, Altreuther M, Menyhei G, Nordanstig J, Clarke M, Rieß HC, 
Björck M, Debus ES. International Variations in Amputation Practice: A VASCUNET Report. Eur J Vasc Endovasc Surg. 2018; 56: 391-399. doi: 10.1016/j.ejvs.2018.04.017. PMID: 29859821

10. McEwen LN, Ylitalo KR, Munson M, Herman WH, Wrobel JS. Foot Complications and Mortality: Results from Translating Research Into Action for Diabetes (TRIAD). J Am Podiatr Med Assoc. 2016; 106: 7-14. doi: 10.7547/14-115. PMID: 26895355

11. American Cancer Society. Cancer Facts \& Figures 2013. Atlanta: American Cancer Society; 2013. https://www.cancer.org/research/cancer-facts$\underline{\text { statistics/all-cancer-facts-figures/cancer-facts-figures-2013.html Accessed on }}$ 27 October 2019.

12. American Cancer Socitey. Colorectal Cancer Facts \& Figures 20142016. Atlanta: American Cancer Society; 2014. Accessed on 27 October 2019.

13. López-Valverde ME, Aragón-Sánchez J, López-de-Andrés A, GuerreroCedeño V, Tejedor-Méndez R, Víquez-Molina G, Jiménez-García R. Perioperative and long-term all-cause mortality in patients with diabetes who underwent a lower extremity amputation. Diabetes Res Clin Pract. 2018; 141:175-180. DOI: 10.1016/j.diabres.2018.05.004. PMID: 29777746

14. Jupiter DC, Thorud JC, Buckley CJ, Shibuya N. The impact of foot ulceration and amputation on mortality in diabetic patients. I: From ulceration to death, a systematic review. Int Wound J. 2016; 13: 892-903. DOI: 10.1111/iwj.12404. PMID: 25601358

15. López-de-Andrés A, Jiménez-García R, Esteban-Vasallo MD, HernándezBarrera V, Aragon-Sánchez J, Jiménez-Trujillo I, de Miguel-Diez J, PalomarGallego MA, Romero-Maroto M, Perez-Farinos N. Time Trends in the 
Incidence of Long-Term Mortality in T2DM Patients Who Have Undergone a Lower Extremity Amputation. Results of a Descriptive and Retrospective Cohort Study. J Clin Med. 2019; 8(10). pii: E1597. DOI: 10.3390/jcm8101597. PMID: 31581755

16. Gök Ü, Selek Ö, Selek A, Güdük A, Güner MÇ. Survival evaluation of the patients with diabetic major lower-extremity amputations. Musculoskelet Surg. 2016; 100: 145-8. DOI: 10.1007/s12306-016-0399-y. PMID: 26965501

17. Huang YY, Lin CW, Yang HM, Hung SY, Chen IW. Survival and associated risk factors in patients with diabetes and amputations caused by infectious foot gangrene. J Foot Ankle Res. 2018; 11:1. DOI: 10.1186/s13047-017-0243-0. PMID: 29312468

18. Wilbek TE, Jansen RB, Jørgensen B, Svendsen OL. Risk Factors for Premature Death in Diabetes Patients who Undergo Amputations below Ankle Level. Exp Clin Endocrinol Diabetes. 2018; 126: 61-65. DOI: 10.1055/s-0043109700. PMID: 28675915

19. Kelly PJ, Clarke PM, Hayes AJ, Gerdtham UG, Cederholm J, Nilsson P, Eliasson B, Gudbjornsdottir S. Predicting mortality in people with type 2 diabetes mellitus after major complications: a study using Swedish National Diabetes Register data. Diabet Med. 2014; 31: 954-62. DOI: 10.1111/dme.12468. PMID: 24750341

20. Desormais I, Aboyans V, Bura A, Constans J, Cambou JP, Messas E, Labrunie A, Lacroix P. Anemia, an independent predictive factor for amputation and mortality in patients hospitalized for peripheral artery disease. Eur J Vasc Endovasc Surg. 2014; 48: 202-7. DOI: 10.1016/j.ejvs.2014.04.005. PMID: 24935912 


\section{Figure legends}

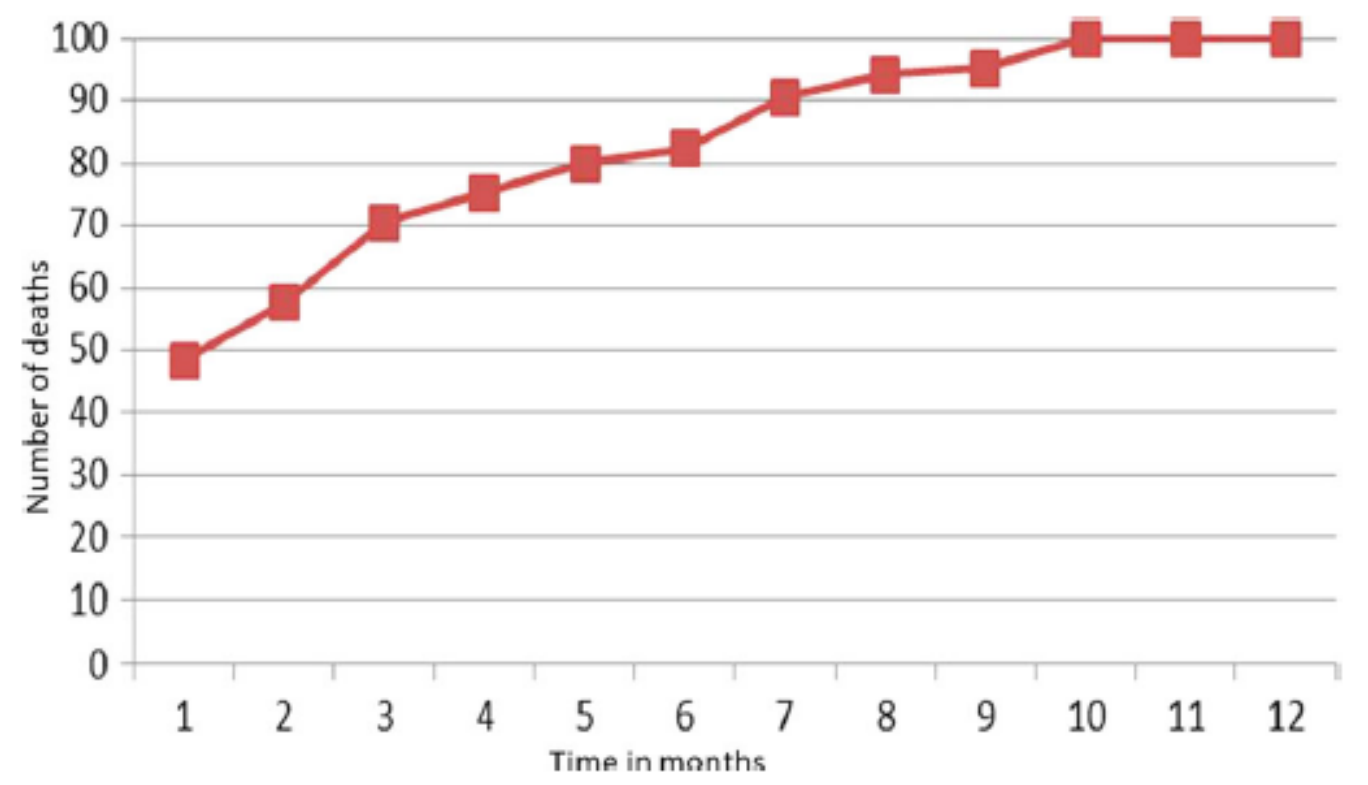

Figure 1. Cumulative monthly mortality of 84 patients who died within 12 months of amputations. $47.5 \%$ of all deaths occurred within 4 months of amputation surgery 

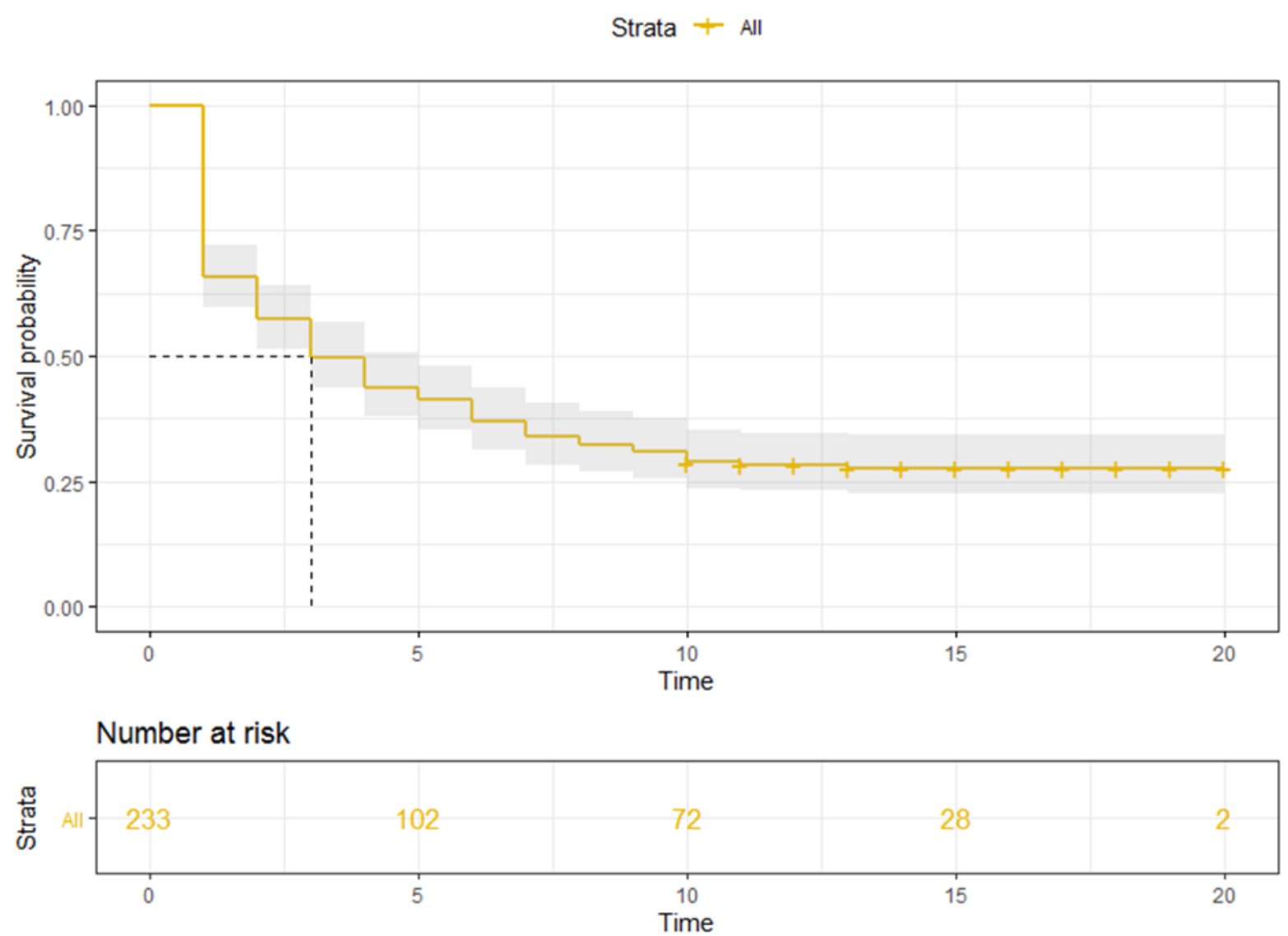

Figure 2: The Kaplan-Meier survival curve following lower extremity amputations over a $10+$ year period among the whole amputation cohort 

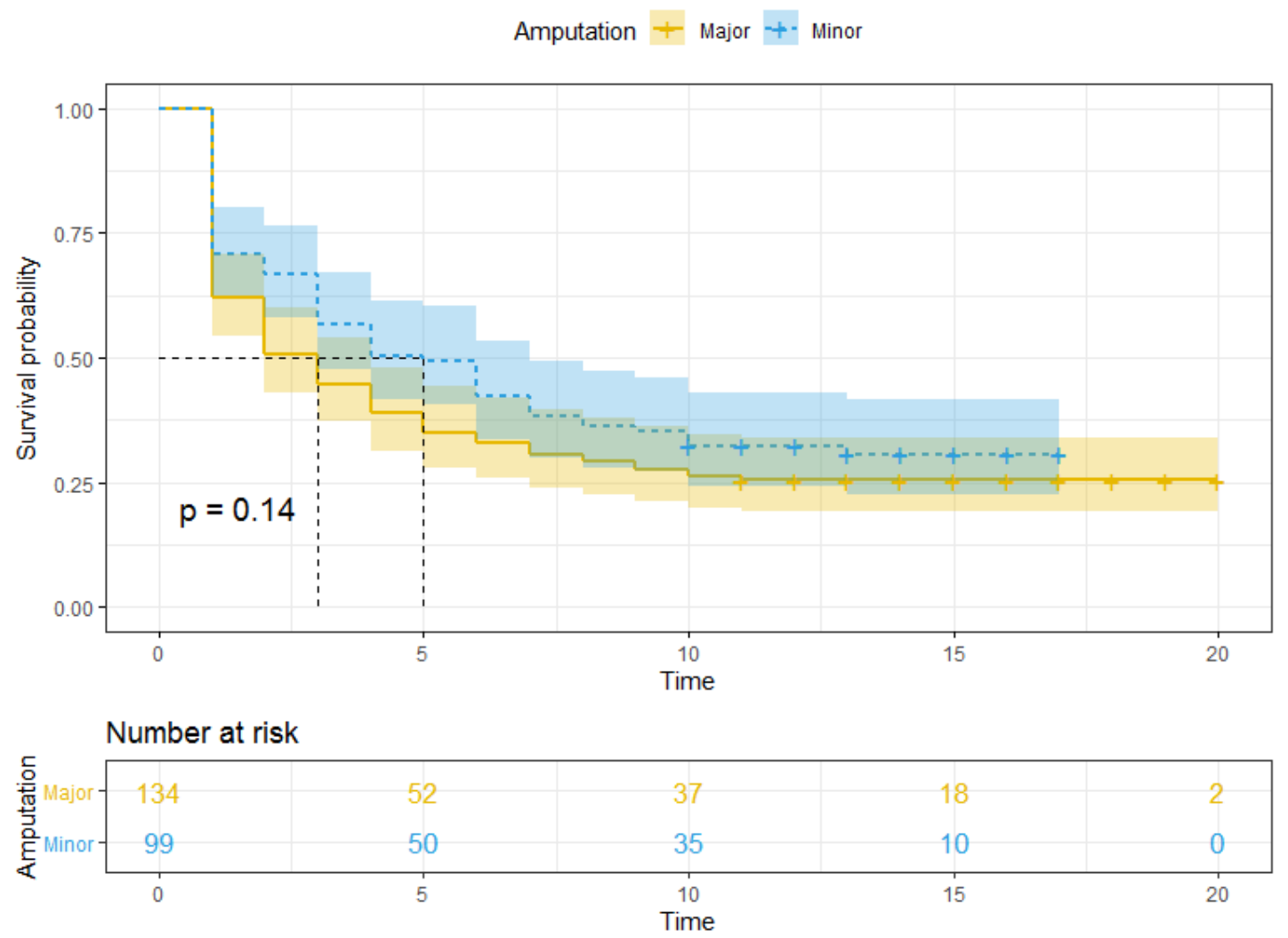

Figure 3: Kaplan-Meier curve showing the survival among patients who underwent major and minor amputations on long-term follow up 


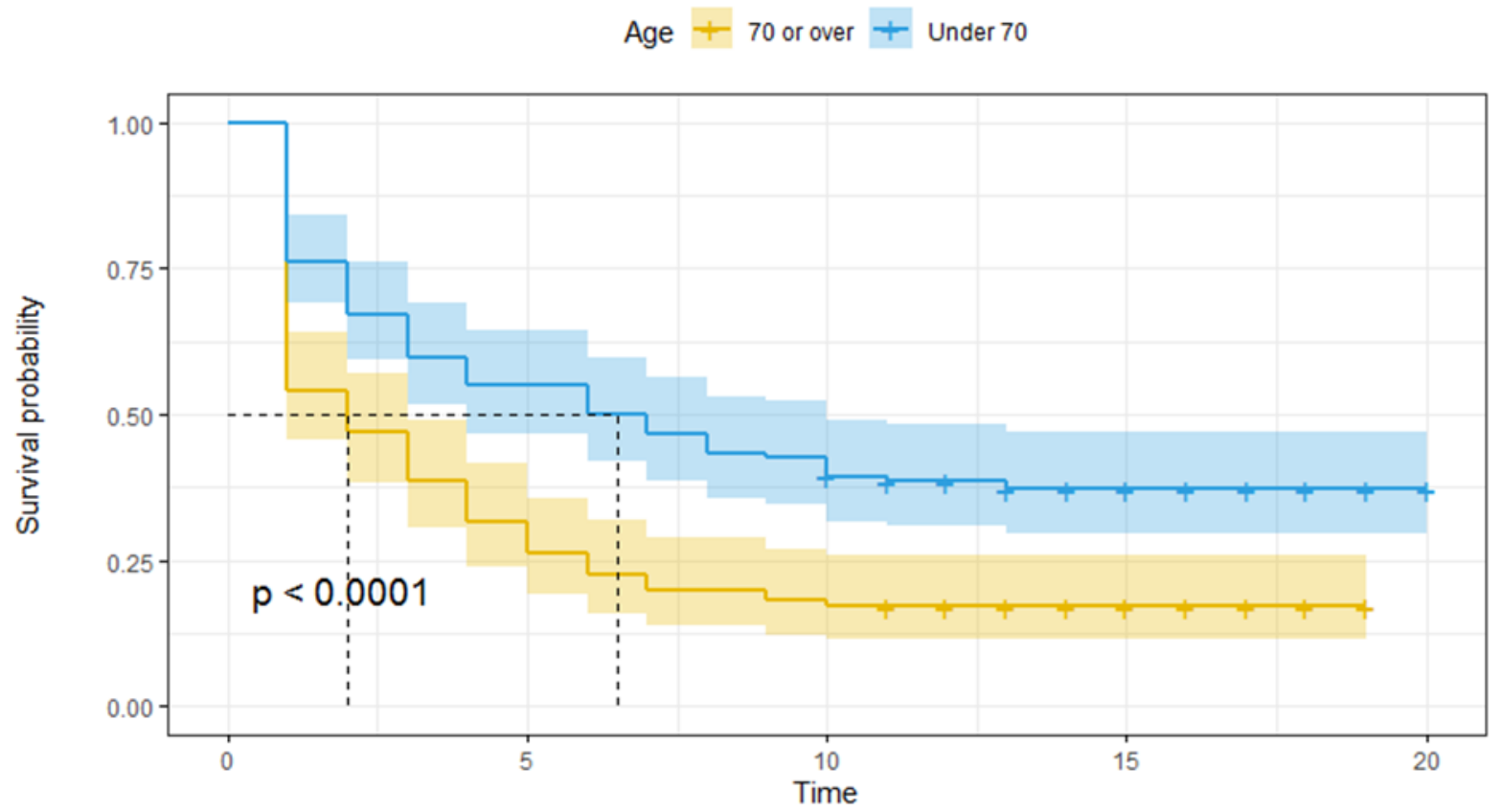

Number at risk

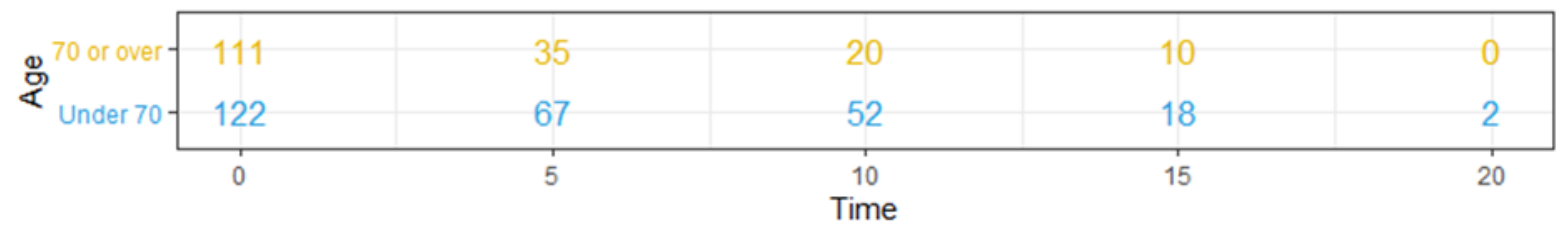

Figure 4. Kaplan-Meier curve showing the survival among patients $\geq 70$ year those below 70 years who underwent lower extremity amputations on long-term follow up

Table 1. Time-specific survival data among patients who underwent lower extremity amputations

\begin{tabular}{cccccc}
\hline Year & N at risk & N of events & Survival & SE & $95 \%$ CI \\
\hline 1 & 233 & 80 & 0.66 & 0.032 & $0.60,0.72$ \\
3 & 134 & 37 & 0.50 & 0.033 & $0.44,0.57$ \\
5 & 102 & 20 & 0.41 & 0.032 & $0.35,0.48$ \\
7 & 86 & 17 & 0.34 & 0.031 & $0.28,0.41$ \\
9 & 75 & 7 & 0.31 & 0.030 & $0.26,0.37$ \\
11 & 66 & 6 & 0.28 & 0.030 & $0.23,0.35$ \\
13 & 45 & 1 & 0.27 & 0.030 & $0.23,0.34$ \\
15 & 28 & 0 & 0.27 & 0.030 & $0.23,0.34$ \\
20 & 2 & 0 & 0.27 & 0.030 & $0.23,0.34$ \\
\hline
\end{tabular}


Table 2 Multivariate analysis showing possible parameters affecting survival after lower extremity amputations

\begin{tabular}{lccccc}
\hline Variable & $\begin{array}{c}\text { Regression } \\
\text { coefficient }(\beta)\end{array}$ & SE & $p$-value & $\begin{array}{c}\text { Hazard ratio } \\
(\mathrm{HR})\end{array}$ & 95\% CI for HR \\
\hline Age at amputation & 0.039 & 0.014 & 0.005 & 1.040 & 1.012 to 1.069 \\
$\begin{array}{l}\text { Amputation, minor vs. } \\
\text { major }\end{array}$ & -0.159 & 0.287 & 0.579 & 0.853 & 0.486 to 1.496 \\
$\begin{array}{l}\text { Sex, male vs. female } \\
\text { Anemia, no vs. yes }\end{array}$ & 0.002 & 0.365 & 0.996 & 1.002 & 0.490 to 2.069 \\
$\begin{array}{l}\text { Dyslipidemia, no vs. yes } \\
\text { Liver dysfunction, no }\end{array}$ & -0.127 & 0.368 & 0.729 & 0.881 & 0.429 to 1.810 \\
vs. yes & -0.581 & 0.330 & 0.079 & 0.560 & 0.293 to 1.069 \\
$\begin{array}{l}\text { Renal impairment, no } \\
\text { vs. yes }\end{array}$ & -0.591 & 0.292 & 0.043 & 0.554 & 0.312 to 0.981 \\
High HbA1C, no vs. yes & 0.275 & 0.297 & 0.353 & 1.317 & 0.736 to 2.355 \\
\hline
\end{tabular}

Likelihood ratio $=23.64, \mathrm{df}=8, p=0.003 ; \mathrm{n}=78$, events $=54(\operatorname{missing}=155)$. 